\title{
A community-based approach to non- communicable chronic disease management within a context of advancing universal health coverage in China: progress and challenges
}

\author{
Nanzi Xiao ${ }^{1}$, Qian Long ${ }^{2}$, Xiaojun Tang ${ }^{1 *}$, Shenglan Tang ${ }^{3}$
}

\begin{abstract}
Paralleled with the rapid socio-economic development and demographic transition, an epidemic of noncommunicable chronic diseases (NCDs) has emerged in China over the past three decades, resulting in increased disease and economic burdens. Over the past decade, with a political commitment of implementing universal health coverage, China has strengthened its primary healthcare system and increased investment in public health interventions. A community-based approach to address NCDs has been acknowledged and recognized as one of the most cost-effective solutions. Community-based strategies include: financial and health administrative support; social mobilization; community health education and promotion; and the use of community health centers in NCD detection, diagnosis, treatment, and patient management. Although China has made good progress in developing and implementing these strategies and policies for NCD prevention and control, many challenges remain. There are a lack of appropriately qualified health professionals at grass-roots health facilities; it is difficult to retain professionals at that level; there is insufficient public funding for NCD care and management; and NCD patients are economically burdened due to limited benefit packages covering NCD treatment offered by health insurance schemes. To tackle these challenges we propose developing appropriate human resource policies to attract greater numbers of qualified health professionals at the primary healthcare level; adjusting the service benefit packages to encourage the use of community-based health services; and increase government investment in public health interventions, as well as investing more on health insurance schemes.
\end{abstract}

\section{Introduction}

Epidemiological, demographic and socio-economic transitions in China over the past few decades have caused a shift from communicable to non-communicable chronic diseases (NCDs) [1]. In 2005, NCDs accounted for an estimated $80 \%$ of deaths and $70 \%$ of disability-adjusted life-years lost (DALY) in China [2]. In 2010, 34\% of Chinese adults over 18 years old (330 million) suffered from hypertension and most were not on appropriate blood pressure control medication [3]. About one-third of Chinese people over 18 years old were overweight, using Body Mass Index (BMI) over 24, and 12\% were

\footnotetext{
* Correspondence: tangxiaoj0726@qq.com

'School of Public Health and Management, Chongqing Medical University, Chongqing, P.R. China

Full list of author information is available at the end of the article
}

categorized as obese (BMI $\geq 28)$ in 2010 [4]. The proportion of overweight adults from 18 to 64 years old increased $15 \%$ between 2007 and 2010, while the proportion of obese adults increased by $57 \%$ during the same time interval $[4,5]$. According to the World Health Organization (WHO) Report of the Global Tobacco Epidemic in 2008, over 300 million Chinese men were cigarette smokers and 100 million men currently under the age of 30 years will die from tobacco use if such a smoking pattern continues [6]. The prevalence and burden of NCDs in China will continue to grow with a rapid aging population and continuing changes in socio-economic development and lifestyle choices which affect health. Collectively, these pose great challenges to the improvement of health and healthcare in China. 
China had a relatively well functioning health system prior to the economic reform launched in the late 1970s. It had faced numerous problems in financing of, and access to, healthcare during the transformation from planned to market economy in 1980s and 1990s. Since the early 2000s, the Chinese government has renewed its efforts to establish a functioning health system to ensure adequate access to essential healthcare for the vast majority of the Chinese population. Universal health coverage is one important goal; ensuring all Chinese people obtain the essential and affordable health services they need without suffering financial hardship. This requires a robust, efficient, and well-financed health system with sufficient capacity, especially in terms of a well-trained and motivated health workforce. It also requires adequate financial protection for access to medicines, technologies and other services.

With a political commitment to universal health coverage, over the past decade China has made notable progress: more than $92 \%$ of the Chinese population is covered by health insurance in 2011[7]; numerous public health interventions launched to tackle both communicable diseases (such as HIV/AIDS, tuberculosis), and NCDs (e.g., hypertension and Diabetes Mellitus (DM)), and adequately funded and implemented communitybased health service delivery system being established; the national essential medicine system strengthened to improve rational use of medicines for better quality and cost control, especially at the community level $[7,8]$; community health centers $(\mathrm{CHCs})$ and community health stations (CHSs) in urban areas; township health centers (THCs) and village health stations (VHSs) in rural areas, empowered to play a key role in improving equitable and affordable access to essential healthcare for the population. Furthermore, the government has developed and implemented a series of measures to enhance the capacity of service provision at these health facilities, including construction and equipment standards for these health facilities, the development of guidelines for general practitioners, and training for primary healthcare providers. There is also an increasing number of primary healthcare facilities at grass-roots which now receive financial supports from both central and local governments [7].

In spite of this progress in strengthening of the health system, significant challenges remain in tackling NCDs in China. With the exception of the Urban Employees' Basic Medical Insurance (UEBMI), many health insurance schemes in China do not offer comprehensive coverage of health services [7-9]. The service benefit packages often prioritize inpatient services - as per the national guidelines developed by the central government $[7,10]$, but most NCD patients require frequent uses of outpatient services. For example, the New rural Cooperative Medical Scheme (NCMS) and Urban Resident Basic
Medical Insurance (URBMI) - jointly financed by the central and province government and with modest premium contribution from individual members - often do not adequately meet the needs of NCD patients. Moreover, well-qualified doctors and nurses in China, like elsewhere in the world, are less likely to work at primary healthcare facilities, which may compromise the quality of care at the community level.

This paper discusses and analyzes the progress and challenges faced when implementing a community-based approach for NCD care and management in the context of advancing universal health coverage in China. First, we discuss the burden of NCDs and challenges in managing these conditions, using hypertension and DM as case studies. Second, we analyze various health policy initiatives related to NCD care and management at the community level, in relation to health financing, and health workforce. Finally, we offer suggestions regarding the effectiveness of a community-based approach addressing NCDs in China.

\section{Burden of NCDs: challenges for China}

Table 1 illustrates the rise of hypertension from 1958 to 2010, based on a series of nationwide epidemiological surveys mainly undertaken by China Center for Disease Control (CDC) [5,11-14]. While these data cannot be directly compared due to differences in study designs and measurements, rising hypertension rates in China are strongly evident, and witnessed in various provinces and cities. For example, $\mathrm{Li}$ and colleagues surveyed 16,364 rural residents over 25 years old in Shandong province located in Eastern China in 2007 and reported an agestandardized prevalence rate of hypertension of $37 \%$ [15]. In a less developed region Ningxia the prevalence rate was $14 \%$ in the period of 2008-2009, reported by another survey [16].

DM is another growing problem in China (Table 2) [12,17-21]. In 2010 the estimated prevalence of diabetes among a nationally representative sample of Chinese adults was $12 \%$ and the estimated prevalence of prediabetes was $50 \%$ [21].

The economic burden caused by both hypertension and DM is heavy. According to the national data, 31.9 billion and 10.7 billion Chinese yuan was spent on hypertension and DM treatment in 2002, which accounted for 5.6\% and $1.9 \%$ of the total national health expenditure respectively [22]. There was no reliable estimation of the economic burden of hypertension and DM in recent years.

\section{Strategies and policies for NCD prevention and management in China}

Most NCDs are associated with preventable risk factors. Effective control of risk factors could reduce the incidence of heart attack, stroke and DM by at least $80 \%$ [23]. 
Table 1 Prevalence rate of hypertension in China 1958 -2010

\begin{tabular}{|c|c|c|c|}
\hline Year & $\begin{array}{l}\text { Prevalence } \\
\text { rate (\%) }\end{array}$ & Data source & Study \\
\hline 1958-1959 & 5.1 & The national sampling survey with adults over 15 years & $\begin{array}{l}\text { Chinese guidelines revision committee of } \\
\text { prevention and treatment for hypertension, } 2006\end{array}$ \\
\hline 1979 1980 & 7.7 & & \\
\hline 1991 & 13.6 & & \\
\hline 2002 & 18.8 & $\begin{array}{c}\text { The national multistage and stratified sampling survey with adults } \\
\text { over } 18 \text { years }\end{array}$ & Li, 2005 \\
\hline 2004 & 18.1 & $\begin{array}{l}\text { Multistage random sampling of adults aged at 18 69 years from } \\
\qquad 79-160 \text { diseases surveillance sites }\end{array}$ & $\begin{array}{c}\text { National center for NCD control and prevention } \\
\text { and China CDC, } 2009\end{array}$ \\
\hline 2007 & 24.9 & & $\begin{array}{c}\text { National center for NCD control and prevention } \\
\text { and China CDC, } 2010\end{array}$ \\
\hline 2010 & 33.5 & & Li, 2012 \\
\hline
\end{tabular}

Table 2 Prevalence rates of diabetes in China 1979 -2010

\begin{tabular}{|c|c|c|c|}
\hline Year & $\begin{array}{l}\text { Prevalence rate } \\
\text { (\%) }\end{array}$ & Data source & Study \\
\hline 1979 & 0.7 & Random sampling in 14 provinces (cities) & $\begin{array}{c}\text { National Diabetes Prevention and Control Cooperative } \\
\text { Group, } 1981\end{array}$ \\
\hline 1994 & 2.5 & $\begin{array}{c}\text { Random sampling of adults aged at 24-64 years in } 19 \text { provinces } \\
\text { (cities) }\end{array}$ & Pan, 1997 \\
\hline 1996 & 3.2 & $\begin{array}{c}\text { Stratified and cluster sampling of adults aged at 20 74years in } 11 \\
\text { provinces (cities) }\end{array}$ & Wang, 1998 \\
\hline 2000 & 6.4 & $\begin{array}{c}\text { Stratified and cluster sampling of adults aged at 35 74years in } 10 \\
\text { provinces (cities) }\end{array}$ & Gu, 2003 \\
\hline 2002 & 2.6 & $\begin{array}{l}\text { Multistage and stratified cluster sampling of adults over } 18 \text { years old } \\
\text { in } 31 \text { provinces }\end{array}$ & $\mathrm{Li}, 2005$ \\
\hline 2010 & 11.6 & $\begin{array}{l}\text { Multistage, probability sampling in a nationally representative } \\
\text { sample } \geq 18 \text { years old }\end{array}$ & Xu, 2013 \\
\hline
\end{tabular}

The incidence and prevalence of these diseases are closely associated with income level, ecological environment, culture and lifestyle [1]. Recently, central and local governments in China have committed to develop and implement a series of strategies including financial, technical and administrative support for NCD prevention and treatment [24]. Table 3 introduces a number of these strategies and programs with associated indicators being used to assess the effectiveness for these interventions.

Primary healthcare facilities at the community level play a key role in the implementation of the strategies and programs. They are mandated to provide essential health services for every resident, especially children, pregnant women, the elderly and patients with NCDs. In 2009, the government allocated 15 Chinese yuan per person per year for the national public health intervention programs; in 2011 the budget increased to 25 Chinese yuan per person per year [7]. In rural areas, $60 \%$ of this funding was earmarked for township health centers to implement public health interventions, while the remaining $40 \%$ allocated to village health stations [25]. Proportions of the total budget specifically for the management of patients with hypertension and DM was $18 \%$ and $7 \%$, respectively [25].
In recent year, China $\mathrm{CDC}$ issued the guidelines of NCD prevention and treatment, advocating the integration of primary, secondary and tertiary prevention for hypertension and DM at the primary healthcare level $[26,27]$. Furthermore, the proposed guidelines tailored interventions targeting three different population groups: 1) the general population; 2) high risk group with characteristics of smoker and obesity, high blood pressure, impaired glucose regulation and high hyperlipidemia; and 3) Hypertension and DM patients. For access of the general population to primary healthcare, standardized personal health profile should be established, containing patient demographic, social characteristics, previous medical records, family medical history, records of physical check-up, and life style, among others. In addition, NCD related health education and promotion services should be provided during outpatient visits to community health centers and stations. Blood pressure should be measured for those over 35 years and older. For the high risk group, annual physical check-up is provided for early detection of NCD patients. For Hypertensive and DM patients, at least four follow-up visits per year can be arranged, with free examinations and tests for blood pressure or glucose. By the end of September 2011, 


\begin{tabular}{|c|c|c|}
\hline Strategies & $\begin{array}{c}\text { Selected Public Health } \\
\text { Programs }\end{array}$ & Selected assessment indicators \\
\hline $\begin{array}{c}\text { - Financial support from each level government } \\
\text { - Advocacy and social mobilization to develop supportive } \\
\text { community environment for NCD prevention and control } \\
\text { - Community health education and promotion } \\
\text { - Clarification of NCD prevention and control responsibility by } \\
\text { different health facilities (e.g. CDC, NCD specialist, CHC etc.) } \\
\text { - Training health practitioners of CHCs on NCD diagnosis, } \\
\text { treatment and rehabilitation services } \\
\text { - Comprehensive control for multiple risk factors including health } \\
\text { guidance on diet, fitness activity and tobacco control etc. } \\
\text { - Promoting NCD patient self-management model and home } \\
\text { services by general practitioners }\end{array}$ & $\begin{array}{l}\text { - Population-based public } \\
\text { health interventions: } \\
\text { - Establishing health file } \\
\text { - Providing health } \\
\text { education and consultant } \\
\quad \text { services } \\
\text { - Screening examination } \\
\text { - Individual-based health } \\
\quad \text { interventions: } \\
\text { - Four times follow up visits } \\
\text { - Health guidance }\end{array}$ & $\begin{array}{c}\text { - Knowledge of population on NCDs: } \geq 70 \% \\
\text { - Knowledge on blood pressure: } \geq 70 \% \\
\text { - Knowledge on blood glucose: } \geq 30 \% \\
\text { - Registration rates: hypertension and DM } \geq 60 \% \\
\text { of local prevalence or national average level } \\
\text { - Management rate of chronic diseases: } \\
\text { hypertension } \geq 35 \%, \mathrm{DM} \geq 30 \% \\
\text { - Control rate of chronic diseases: hypertension } \geq \\
50 \%, \mathrm{DM} \geq 50 \%\end{array}$ \\
\hline
\end{tabular}

CHCs: community health centers; CDC: center for disease control; DM: diabetics mellitus; NCD: non-communicable diseases

433 million people have established their personal health record cards, and more than 59 million hypertensive and DM patients are now under the NCD case management system in which community health centers and stations in urban areas and township health centers and village health stations in rural areas are key players for these disease prevention and control activities. Other government strategies for prevention, treatment and management of NCDs included the establishment of three national health insurance schemes to facilitate access to clinical care the urban employee basic medical insurance (UEBMI), urban resident basic medical insurance (URBMI) and new rural cooperative medical scheme (NCMS). The Chinese Ministry of Health also developed a national essential medicines list and relevant policies which encourage the rational use of medicines at primary health facilities at the community level.

\section{Challenges in addressing NCDs for China}

Despite the good progress made to control and prevent NCDs, great challenges remain in China. One challenge is poor knowledge and low awareness about NCDs, particularly at the poor and rural community level. In 2010, only one quarter of DM patients in rural areas were aware of their illness, compared to $40 \%$ among urban patients; One fifth of rural patients and two fifths of urban patients received treatment for diabetes [21]. A significant disparity in awareness of NCDs was also found across different socio-economic development regions [21].

While the primary healthcare facilities at the community level are at the center of NCD prevention and management activities, the quantity and expertise of health professionals at these facilities are far from optimal [28]. The total number of primary healthcare workers in urban areas was about three million in 2011; about three qualified doctors/assistants and 3.32 registered nurses per 1,000 population [29]. In rural areas, the ratio of qualified health workers and registered nurses to 1,000 population was only 1.32 and 0.98 , respectively, in the same year [29].
Furthermore, the majority of health professionals in both rural and urban primary healthcare facilities had only $2-3$ years of medical education/training, and only $8 \%$ of health professionals had a university/college degree. This is due largely to the fact it is difficult to attract new medical and public health graduates, and retain qualified professionals in these facilities. Since the economic reform, the income level of healthcare workers in China has been closely linked with their capacity of revenue generation through user fee charges. The sources of income for most health professionals at the primary healthcare level have often come from drug sales and provision of profitable services. As part of the recent health system reform, the government has now allocated more funds to primary healthcare facilities to encourage the provision of quality services. As a result of the reform, the income of healthcare professionals at this level has no longer been driven by over-provision of drugs and services. The incomes of these doctors and nurses have gradually increased, but still remain relatively low [30]. In addition, opportunities for career development and quality education for the children of health professionals are important factors affecting their preference to work in urban health facilities, instead of rural ones [Liu, personal archive, 2013].

Existing health insurance policies in China also presents great challenges in NCD care and management. The service benefit packages offered by the main health insurance schemes in urban and rural areas differ dramatically. These schemes also tend to prioritize the coverage of inpatient services, while the coverage of outpatient services is either inadequate or lacking. These policies often do not go far enough in meeting the treatment needs of NCD patients in particular [10]. While the above-mentioned three health insurance schemes cover 1.3 billion people over $90 \%$ of the total population in China - the reimbursement rate for inpatient service expenditures by the new rural cooperative medical scheme, for example, ranges between $40-70 \%$ in many regions [7]. The report on chronic disease in China in 2006 shows, average expenses 
per hospital admission for hypertension and DM was 4,338 Chinese Yuan and 5,276 Chinese Yuan, respectively, accounting for 1.5 times and 1.8 times of average annual per capita income of the rural residents, and for $46 \%$ and $56 \%$ of average annual per capita income of urban residents, respectively [31]. In addition, the proportion of NCMS reimbursement for outpatient service expense was generally much lower than what was reimbursed for inpatient service expenses. One study conducted in Shandong and Ningxia found only around 10\% of outpatient service expenditure reimbursable in rural areas in 2006 [32]. As a result, the economic burden of healthcare expenditure placed on NCD patients was pretty significant that $14-15 \%$ of rural households with NCD patients spent more than $40 \%$ of their non-food expenditure on chronic disease treatment in 2006 [32], a threshold for catastrophic health expenditure defined by WHO.

\section{Way forward for a community-based approach to NCD care and control in China}

The World Bank (2011) has recently raised serious concerns about epidemics of NCDs in China in its report entitled "Toward a healthy and harmonious life in China: Stemming the rising tide of NCDs". It has proposed a comprehensive strategy for addressing this growing problem and tackling its challenges. As NCD control requires a continuum of care and extensive social support, a community-based approach has been acknowledged as one of the most cost-effective prevention and control measures [33]. We firmly believe that a community-based approach helps to develop "early detection, early diagnosis and early treatment and systematic patient management", as well as having the added benefit of building a healthy and friendly community environment through community advocacy and participation, and helping to raise awareness and knowledge of NCDs in the population [33].

For the community-based approach to NCD prevention and control to be effective in China, we offer three recommendations in this paper. First, China needs to develop appropriate human resource policies to attract more qualified health professionals to work at primary health facilities, especially in rural areas. There have been a number of experimental studies on how to retain qualified health professionals in rural or remote areas. Findings emanating from these studies indicate the need to including both financial and non-financial incentives, including policies on increasing income level, supporting medical education, and providing more professional career development opportunities. The government of China needs to seriously consider the development of appropriately tailored human resource policies that can meet the needs of different local contexts.
Second, China needs to adjust the service benefit packages offered by the health insurance schemes to be in favor of the use of community-based health services. China has achieved universal health insurance coverage, but most schemes prioritize the coverage of inpatient care because it was believed that expensive inpatient care was the major reason for pushing people into poverty. However, many studies in China and other countries have identified substantial costs incurred from frequent outpatient visits for NCD treatments. That financial burden has become a major factor resulting in medical impoverishment [10,34]. Therefore, the design of benefit packages should be re-visited and modified, as strong evidence has arisen. A focus on prevention and control of NCDs should also help to further mitigate the medical and social costs of NCDs.

Lastly, China needs to continue to increase its investment in public health intervention programs and financial support to health insurance schemes. Increased funding from both central and local governments needs to be directed to the less developed regions and poorer rural areas to support NCD interventions, and health insurance schemes. In addition, it is equally important to strengthen monitoring of the use of funding for public health interventions, at the primary healthcare community level. Finally, the population, especially the poor, needs to be protected financially from high costs related to NCD treatments.

\section{Abbreviations \\ BMI: Body Mass Index; CHCs: CDC: China Center for Disease Control; Community Health Centers; CHSs: Community Health Stations; DALY: Disability-Adjusted Life-Years lost; DM: Diabetes Mellitus; NCDs: Non- Communicable Diseases; NCMS: New rural Cooperative Medical Scheme; THCs: Township Health Centers; UEBMI: Urban Employees Basic Medical Insurance; URBMI: Urban Resident Basic Medical Insurance; VHSs: Village Health Stations; WHO: World Health Organization.}

\section{Competing interests}

The authors declare no competing interests.

\section{Authors' contributions}

ST and QL developed the outlines of the paper. NX, together with ST and $\mathrm{QL}$, drafted the paper. XN did literature review. XT participated in the literature review and the paper writing. All the authors commented on and approved the final version of the paper.

\section{Declarations}

The cost of funding for this article has been covered by the authors. This article has been published as part of BMC Public Health Volume 14 Supplement 2, 2014: Responsive health systems: working with the community on control of non-communicable diseases (NCDs). The full contents of the supplement are available online at http://www. biomedcentral.com/bmcpublichealth/supplements/14/S2.

\section{Authors' details}

'School of Public Health and Management, Chongqing Medical University, Chongqing, P.R. China. ${ }^{2}$ Global Health Research Center, Duke Kunshan University, Kunshan, P.R.China. ${ }^{3}$ Duke Global Health Institute, Duke University, Durham, NC, USA. 
Published: 20 June 2014

\section{References}

1. Lang T, Rayner G: Ecological public health: the 21st century's big idea? An essay by Tim Lang and Geof Rayner. BMJ 2012, 345:e5466.

2. Wang $L$, Kong $L, W u F$, Bai $Y$, Robert B: Preventing chronic diseases in China. Lancet 2005, 366:1821-1824.

3. Li YC, Wang LM, Jiang Y, Li XY, Zhang M, Hu N: Prevalence of hypertension among Chinese adults in 2010. Chinese Journal of Preventive Medicine 2012, 46(5):409-413.

4. National Center Chronic and Non-communicable Disease Control and Prevention, Chinese Center for Disease Control and Prevention: Report on chronic disease and risk factor surveillance in China 2010. Beijing: Military Medical Science Press; 2012.

5. National Center for Chronic and Non-communicable Disease Control and Prevention: Report on chronic disease risk factor surveillance in China 2007. Beijing: People's Medical Publishing House; 2010.

6. World Health Organization: WHO report on the global tobacco epidemic, 2008: The MPOWER package. Geneva: World Health Organization; 2008

7. Yip WC, Hsiao WC, Chen W, Hu S, Ma J, Maynard A: Early appraisal of China's huge and complex health-care reforms. Lancet 2012, 379(9818):833-842.

8. Tang S, Brixi H, Bekedam H: Advancing universal coverage of healthcare in China: translating political will into policy and practice. Int I Health Plann Manage 2013.

9. Brixi H, Mu Y, Targa B, Hipgrave D: Engaging sub-national governments in addressing health equities: challenges and opportunities in China's health system reform. Health Policy Plan 2013, 28(8):809-824.

10. Yip W, Hsiao W: Non-evidence-based policy: How effective is China's new cooperative medical scheme in reducing medical impoverishment? Soc Sci Med 2009, 68(2):201-209.

11. Chinese Guidelines Revision Committee of Prevention and Treatment for Hypertension: Chinese guidelines of prevention and treatment for hypertension (2005 revision edition). Beijing: People's Medical Publishing House;Liu LS and Gong LS 2006:

12. Li L, Rao K, Kong L, Yao C, Xiang H, Zhai F, Ma G, Yang X, the technical working group of China National Nutrition and Health Survey: A description on the Chinese national nutrition and health survey in 2002. Chinese Journal of Epidemiology 2005, 26(7):478-484.

13. National Center for Chronic and Non-communicable Disease Control and Prevention, Chinese Center for Disease Control and Prevention: Report on chronic disease risk factor surveillance in China, 2004. Beijing: Peking Union Medical College Press; 2009.

14. Li YC, Wang LM, Jiang Y, Li XY, Zhang M, Hu N: Prevalence of hypertension among Chinese adults in 2010. Chinese Journal of Preventive Medicine 2012, 46(5):409-415.

15. Li H, Meng Q, Sun X, Salter A, Briggs NE, Hiller JE: Prevalence, awareness, treatment, and control of hypertension in rural China: results from Shandong Province. J Hypertens 2010, 28(3):432-438.

16. Gong J, Jia SB, Ma L: Prevalence of hypertension and its risk factors among rural residents in Ningxia. Chinese Preventive Medicine 2011, 12(3):227-229

17. National Diabetes Prevention and Control Cooperative Group: A survey of diabetes prevalence in a 300000 population from 14 provinces of China. Chinese journal of internal medicine 1981, 20(11):678-683.

18. Pan XR, Yang WY, Li GW, Liu J, National Diabetes Prevention and Control Cooperative Group: Prevalence of diabetes and its risk factors in China, 1994. Diabetes Care 1997, 20(11):1664-1669.

19. Wang K, Li T, Xiang H: Study on the epidemiological characteristics of diabetes mellitus and IGT in China. Chinese Journal of Epidemiology 1998 19(5):282-285.

20. Gu D, Reynolds K, Duan X, Xin X, Chen J, Wu X, Mo J, Whelton PK, He J, InterASIA Collaborative Group: Prevalence of diabetes and impaired fasting glucose in the Chinese adult population: International Collaborative Study of Cardiovascular Disease in Asia (InterASIA). Diabetologia 2003, 46(9):1190-1198.

21. Xu Y, Wang L, He J, Bi Y, Li M, Wang T, Wang L, Jiang Y, Dai M, Lu J, Xu M, Li Y, Hu N, Li J, Mi S, Chen CS, Li G, Mu Y, Zhao J, Kong L, Chen J, Lai S, Wang W, Zhao W, Ning G, 2010 China Non-communicable Disease Surveillance Group: Prevalence and control of diabetes in Chinese adults. JAMA 2013, 310(9):948-959.
22. Wang JS, Zhang QJ, Jin SG: Burden of diseases caused by hypertension and diabetes in China. Journal of Public Health and Preventive medicine 2007, 18(3):27-31.

23. World Health Organization: 2008-2013 Action plan for the global strategy for the prevention and control of non-communicable diseases. Geneva: World Health Organization; 2008.

24. The People's Republic of China National Health and Family Planning Commission: Chronic Disease Prevention and Treatment Work Plan (2012-2015)., [http://www.gov.cn/gzdt/2006-05/12/content_279061.htm] (accessed 12 March 2014).

25. Yang $L$, Cui $Y$, Han $H, X u X D$ : Study on the responsibilities and allocation of funds of national basic public health items in rural medical institutions. Chinese Journal of Women and Children Health 2011, 2:51-54.

26. Liu LS: China hypertension prevention and treatment guideline (2010 edition). Chinese Journal of Hypertension 2011, 19(8):701-708.

27. Chinese Diabetes Society: China guideline for Type II diabetes (2010 edition). Beijing: Peking University Medical Press; Yang WY, Ji LN, Lu JM, Weng JP, Jia WP, Zhou ZG and Zhou DJ 2010:

28. Zhou Y, Fang Z: Analysis of the human resource allocation in community healthcare facility of China. Medicine and Society 2008, 12:6-8.

29. National Bureau of Statistics of China: China Health Statistical Yearbook (2012). Beijing: Peking Union Medical College; 2012.

30. Yip WC, Hsiao W, Meng Q, Chen W, Sun X: Realignment of incentives for health-care providers in China. Lancet 2010, 375(9720):1120-30.

31. Chinese Center for Disease Control and Prevention: Report on chronic disease in China, 2006. 2006, Available from [http://www.chinacdc.cn/ jdydc/05/P0200605123217538575667461530.pdf] (accessed 12 March 2014).

32. Sun Q, Liu X, Meng Q, Tang S, Yu B, Tolhurst R: Evaluating the financial protection of patients with chronic disease by health insurance in rural China. International Journal for Equity in Health 2009, 8:42.

33. The World Bank: Toward a Healthy and Harmonious Life in China: Stemming the Rising Tide of Non-Communicable Diseases. Washington, DC: The World Bank; 2011.

34. Hu J, Rao K, Qiang J, Wu J: The study of economic burden of chronic non-communicable diseases in China. Chinese Journal of Prevention and Control of Chronic Non-communicable Disease 2007, 15(3):189-193.

doi:10.1186/1471-2458-14-S2-S2

Cite this article as: Xiao et al:: A community-based approach to noncommunicable chronic disease management within a context of advancing universal health coverage in China: progress and challenges. BMC Public Health 2014 14(Suppl 2):S2.

\section{Submit your next manuscript to BioMed Central and take full advantage of:}

- Convenient online submission

- Thorough peer review

- No space constraints or color figure charges

- Immediate publication on acceptance

- Inclusion in PubMed, CAS, Scopus and Google Scholar

- Research which is freely available for redistribution 